\title{
Living in Harmony: Designing a multi-functional education facility that has positive sustainable impact on Environment and Society
}

\author{
Christian van Someren, Johnmary Migadde, Mitavachan $\mathrm{H}^{*}$, Mohamed Abdelrazik, Samuel Goda \& Hans Holtorf. \\ Postgraduate Programme Renewable Energy (PPRE), University of Oldenburg, Germany \\ *Corresponding author: mitavachan@gmail.com
}

\begin{abstract}
A unique way of teaching practical aspects of renewable energy technologies has been experimented in the University of Oldenburg since 1987. An energy laboratory (Energielabor), built in 1982 and powered by renewable energy sources, has been used for practical training, lectures and office space for the staff and students engaged in the field of renewable energy at the University. After 30 years of service, this Energielabor requires revision and needs to be rebuilt to meet the needs of present age. In this direction, as part of a module named 'Case Study', PPRE masters' students assessed the locally available renewable energy resources and estimated the energy demand for a newly proposed design for the upcoming new Energielabor. This paper presents the first results of these energy demand and resource assessments, along with highlighting the didactical concepts and motivations behind the newly proposed design.
\end{abstract}

Keywords - Energy laboratory, Renewable Energy education and training, PPRE, solar energy and green building

\section{INTRODUCTION}

In Oldenburg, Germany, an innovative international master program focusing on renewable energy technologies has been offered since 1987 [1]. But, even before this program was started, when the discussion about renewable energy was only beginning, a group of researchers in the University of Oldenburg came together and started a project to demonstrate the usability of renewable energies in unfavorable meteorological conditions for producing energy. This project led to the establishment of a demonstration and research building called 'Energielabor' (the German term for Energy $\mathrm{Lab}$ ) in 1982, whose energy requirements were met with the locally available renewable energy sources, especially wind and solar. This lab served as a nodal point in the growth of renewable energy education in the University of Oldenburg since then. At present, this building is home to several international master programs wherein students and staff share the building for practical training, lectures and office space. Now, after serving for around 30 years, the building is to be replaced by a new facility or renovated in order to take care of growing needs for renewable energy education and the building users' demands. Hence, in order to identify and understand the new requirements and usable resources available, PPRE students assessed the locally available resources and estimated the energy demand for a newly proposed design for the New Energy lab.

It should be noted that the work presented here is the outcome of a practice oriented learning module named Case
Study, offered as part of PPRE curriculum. In Case Study, students' task is to develop the (renewable) energy supply system for an energy service. Milestones in Case Study are the determination of renewable energy potential at a given site, determination of energy demand and load pattern to meet the identified energy service, the system design and the economical analysis of the proposed systems. A final presentation to an interested audience from the public and the campus community is the highlight of the module.

The initiative to erect the 'New Energy Lab' began in 2012 with the definition of space demand analyses for the proposed building by PPRE 2011-13 students. The architecture students of Jade Hochschule subsequently proposed an architectural design for the New Energy lab. In continuation of this work, PPRE 2012-14 students investigated the energy supply system and energy demand for the chosen building design. This paper summarizes the first results of energy demand and resource assessments carried out by PPRE 2012-14 students. In addition, some of the key design criteria and design philosophy that has to be taken into account while developing the final design for New Energy Lab are also highlighted in this paper.

\section{CONCEPT FOR THE NEW ENERGY LAB}

The key factors that must be taken into account while designing the proposed energy lab are discussed below. An optimal balance between the stated objectives should be found, without them upsetting one another. The three main objectives which the newly proposed Energy lab should be able to meet are as follows.

\section{A. A Multi-Functional Building}

It is crucial for any building to be able to function the way it was intended and to properly serve its users. In this case, the proposed building should deliver several functions, such as, providing facilities for lectures, lab courses, research, study and staff. What this implies is that the proposed building must provide the resources necessary to carry out these academic and organizational activities in an agile way.

\section{B. A Learning Environment - Impact on the campus community and the general public}

The New Energy lab should not only provide the above mentioned functions, but should also be able to teach the users something about renewable energies. In essence, the proposed 
building must deliver a message in regards to clean energy technologies and sustainability concepts.

One of the academic goals of this building should be to provide space for teaching staff and students to see the implementation of potential renewable energy technologies and integrate all potential technologies interactively in the practical curriculum, outdoor and indoor labs. Meanwhile, the aesthetic aspects should reflect the green concept and how the building fits within the environment. Virtual tours and web portals might be an option to educate students abroad who cannot visit to the building in person.

The building should have a reserve space for demonstrating recent technological advancements in renewable energy, which in turn will encourage further innovation and research among the academia. The integration of different renewable energy labs with the building design itself should be given foremost importance. The aesthetics of the building, integration of real performance data of renewable energy sources into the web portals and virtual building tours (as in EWE-Zentrum; [2]) should be incorporated in appropriate ways in order to send a green message to society at large.

Lastly, the building design philosophy should be built on the understanding that teaching and learning about renewable energies in an environment that is supported by renewable energies, rather than in an environment reflecting conventional energies, will lead to a new dimension of apprehension amongst the academia and general public.

\section{An environmentally friendly design}

Traditionally, building resources would be provided via a grid connection and importing resources in an unsustainable manner. However, the upcoming New Energy lab is desired to have a positive impact on the environment. This means that the building energy resources cannot simply be harnessed from anywhere. Instead, the building environment should be assessed for the locally available resources, and the building should be designed in such a way to harness these local resources in a sustainable manner. For this to happen, the building should incorporate both passive and active concepts right from its inception stage. Passive concepts such as daylight harvesting and increased solar gain are one of the desired cornerstones that should be adhered to during the conceptual design. The active concepts involve adhering to strict energy efficient measures and installing more renewable energy technologies to meet the final energy demand of the building.

\section{METHODOLOGY}

In this section, the general design requirements and adopted procedure to conduct energy demand survey and resource assessment for the New Energy Lab will be presented.

In this study, the authors want to apply renewable energy technologies to effectively power a building as well as provide a learning experience by integrating a variety of renewable energy technologies and energy efficiency measures into the building design itself. The approach adopted to meet these requirements began with an analysis of the given building design and orientation, a study of available technologies, a detailed resource assessment as well as an energy demand survey. The demand requirements and running of the building were determined by consulting the project stakeholders, specifically, the facility managers and building users.

\section{A. Building design/structure}

The proposed building will be oriented due south and will have primarily triple glazed windows on the south, east and west faces in order to maximize extractable solar energy. In addition, the building's north face and roof will be primarily composed of insulated concrete to reduce thermal losses, especially during winter (see Fig. 1).

The architectural space demand survey was carried out by the PPRE 2011-13 students, wherein they interviewed the relevant University staff and determined a detailed picture for the space requirements based on the feedbacks received [3]. Table 1 summarizes the final results of this survey.

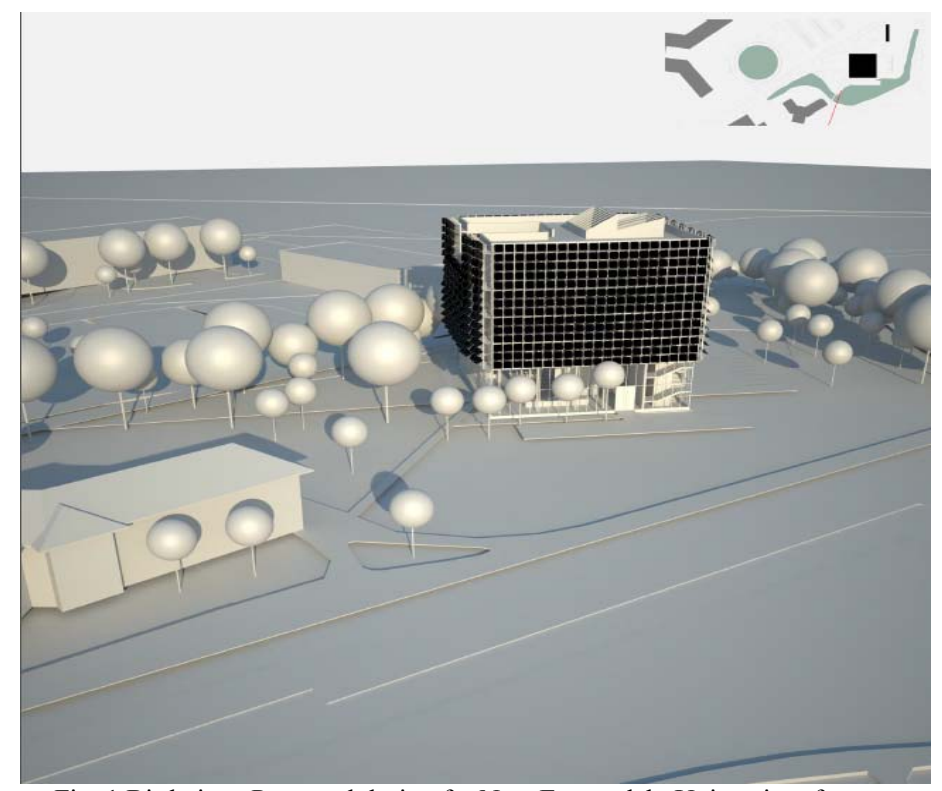

Fig. 1 Bird view: Proposed design for New Energy lab, University of Oldenburg (Lat-53.15 $\mathrm{N}$, Lon-8.16 ${ }^{\circ} \mathrm{E}$ ) [Adopted with due permission from

Janssen and Varelmann, Jadehochschule architectural competition 2012]

\section{B. Demand survey}

The demand survey was divided into an electrical and thermal part. For the electrical demand survey, the power ratings of all equipment to be used for the proposed building were obtained along with the details of daily, seasonal and annual consumption patterns. Some major load types considered were: energy lab equipment, lighting systems, computers and IT equipment, kitchen appliances, ventilation systems and other building infrastructure (e.g. lift).

To understand the building's thermal demand, the factors first considered are sources of heat gains and heat losses. The difference between total heat gains and total losses gives the building's net heating or cooling demand. For the thermal demand, the authors considered internal and solar heat gains, as well as transmission and ventilation heat losses. Internal heat gains include the metabolic heat rate produced by occupants (roughly $130 \mathrm{~W}$ per person; [4]) and the heat 
released by appliances, lab equipment and lighting. Solar heat gains were obtained from the solar radiation transmitted through the building's windows and walls. Heat losses are the result of conduction, convection and radiation losses through the building's envelope due to natural heat gradients from the building to the surrounding environment. Additional losses occur from ventilation, which forcibly removes hot air from the building and replaces it with cold air from the environment or by inevitable leakage of the building envelope.

TABLE 1

SPACE DEMAND ANALYSIS FOR NEW ENERGY LAB [3]

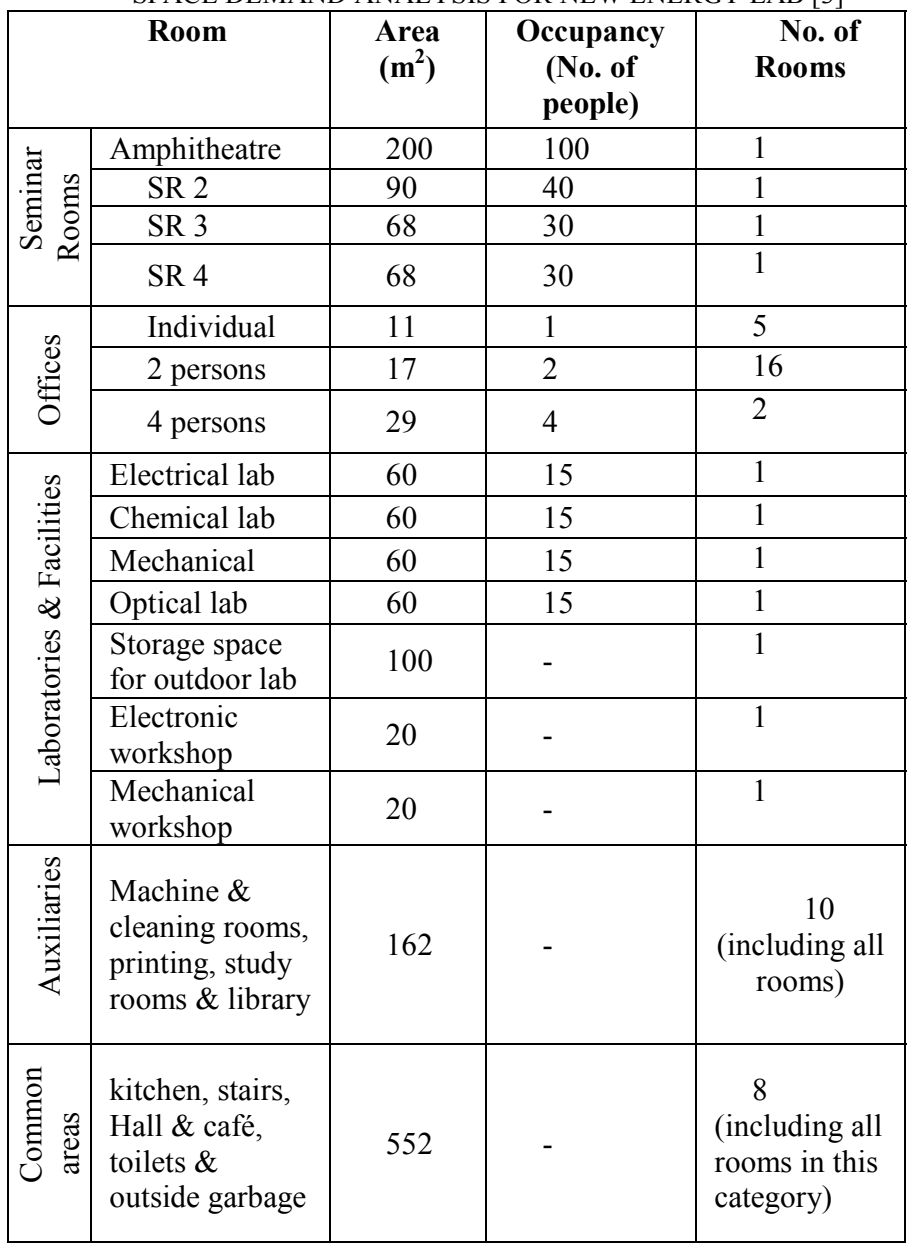

\section{Resources studied}

The following resources and technologies were analyzed: thermal and photovoltaic technologies using solar energy, heat pumps using geothermal energy, combined heat and power plants, wind energy converters and anaerobic digesters (biogas).

\section{RESULTS}

In this section, the results obtained from the demand survey and resources assessment will be described.

Fig. 2 shows the estimated electrical consumption of the New Energy lab across the year. It clearly shows that the electrical consumption is higher on winter days wherein the need for space heating is large and laboratories will be conducted indoors. Other small variations are due to festival and summer holidays. The estimated total electricity consumption for the building is $180 \mathrm{MWh}$ per year; $24 \%$ for computers and IT equipment, $30 \%$ for laboratories and infrastructure, $26 \%$ for illumination and kitchen equipment, and $36 \%$ for ventilation systems. Also, it should be noted that this generated demand profile already includes the application of energy efficiency measures, significantly for lighting loads.

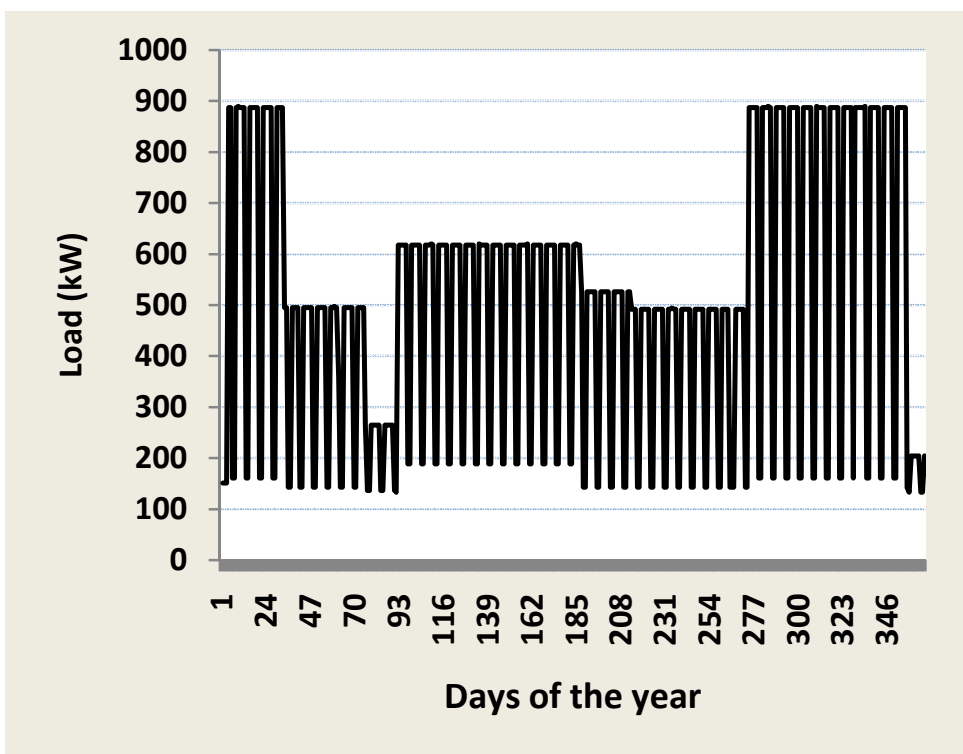

Fig. 2 Electrical load demand of the New Energy Lab

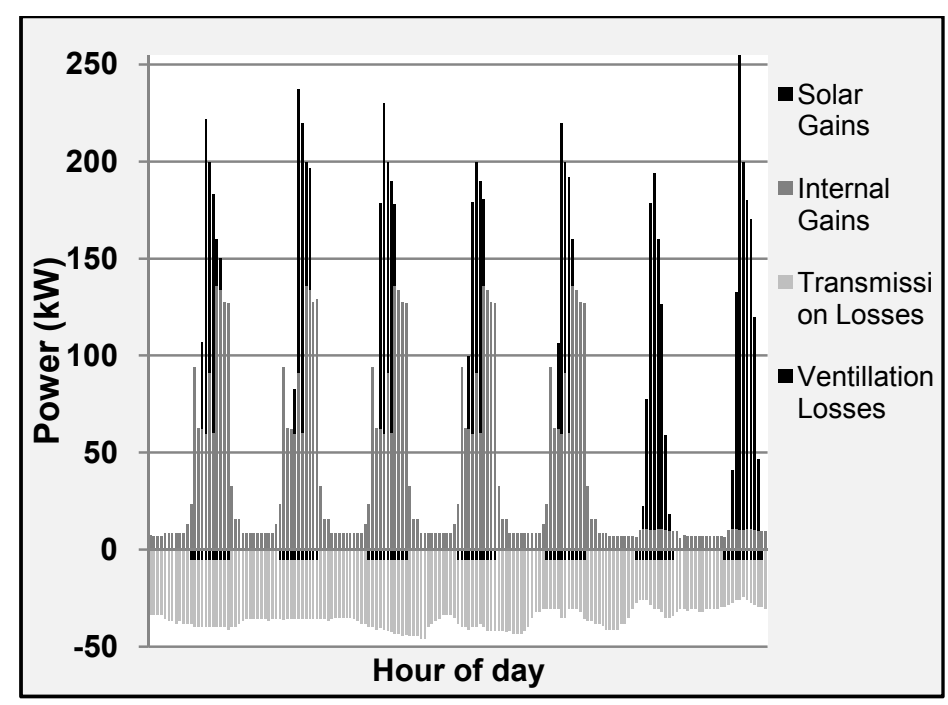

Fig. 3 Thermal energy demand balance in winter time

Fig. 3 shows the thermal demand profile during a typical winter week (from January 7 to January 14) in the northern hemisphere when there is very little solar irradiation and relatively cold ambient temperatures. The energy supplied is given by the difference between heat losses and gains. It can be seen that solar gain is highest, followed by internal gains. The ventilation losses and transmission losses, shown on negative side in Fig. 3, are more or less constant. The range of transmission losses is not that high. The implication is that the solar gains in the day can be utilized to keep the building warm during the night during winter if proper thermal energy 
storage options are installed and integrated with the building heating systems. A similar simulation for a typical summer month showed more solar gains as outdoor temperatures are relatively warm. Ventilation losses are present throughout the year, but less in summer months since incoming air does not need to be preheated as much. Accordingly, transmission losses are also reduced during the summer.

Both for wind and solar energy, the measured resource data for the proposed site was readily available from the Oldenburg University's meteorological station. The wind resource assessment showed that the average wind speed for the site is $2.5 \mathrm{~m} / \mathrm{s}$ which is considered to be too low to install a wind turbine, both from energy and economical points of view. For biogas resource, after conducting a survey within a one kilometer radius from University of Oldenburg, it was estimated that 1.75 tones of cow dung and $100 \mathrm{~kg}$ of foodwaste will be available on a daily basis. These resources can be used to generate around $100-140 \mathrm{kWh}$ of electrical and $110-190 \mathrm{kWh}$ of thermal energy simultaneously using a Combined Heat and Power plant (CHP). Geothermal source for electricity generation was found to not be viable due to low underground temperatures profiles for the Oldenburg region $\left(110^{\circ} \mathrm{C}\right.$ at $3000 \mathrm{~m}$ depth), but it is viable for space heating using heat pumps. Part of heating load during winter can be met by utilizing the geothermal heat extracted at $9^{\circ} \mathrm{C}$ from a depth of $100 \mathrm{~m}$. In order to integrate the geothermal heat pump and/or biogas thermal energy with other thermal components of the building, dynamic simulation of the whole building system, including each of these resources, should be carried out.

The daily Global Horizontal Irradiation value for the site varied from $0.5 \mathrm{kWh} / \mathrm{m}^{2} /$ day in December to $5 \mathrm{kWh} / \mathrm{m}^{2} /$ day in May. The total yearly Global Horizontal Irradiation available at this site is around $990 \mathrm{kWh} / \mathrm{m}^{2} /$ year. Fig. 4 shows the power supplied by two different photovoltaic scenarios compared to the electricity demand of the building. It is estimated that, in the poly-crystalline scenario, $52 \%$ of the required electric energy can be supplied by PV panels covering $816 \mathrm{~m}^{2}$ of building area, including area available on rooftop and side walls. For comparison, current thin film photovoltaic technology can only provide $18 \%$ of the electricity demand covering $1245 \mathrm{~m}^{2}$ of available building area. This shows that solar PV has the potential to play a major role in the building energy supply portfolio. However, as solar resource is intermittent, this technology should be coupled with storage options and grid connection in order to take care of demand on a continuous basis.

Conversely, considerable part of the building's heating requirement can be met by using proper insulation and maximizing solar energy gains during the winter. Application of solar passive concepts and proper building orientation, as described in the previous section, will help in reducing external heating demand of the building. In addition, some form of temporary heat storage, such as heat pumps coupled with underground water reservoirs, may be required during the coldest weeks of the year. Cooling of the building becomes an issue during summer months, but it is likely that proper solar shading combined with good ventilation can account for heat gains. The impact on electricity and thermal demands resulting from integrating passive solar concepts into the building design still remains to be explored in detail.

More details on the assumptions and results of this study can be found in [5]. Lastly, it is noteworthy to mention that learning modules like Case Study provide real world exposure to the students and teach them how to bring theory into practice, along with bringing interdisciplinary cooperation between students as they would be encouraged to work in teams. Hence, these kinds of modules should be encouraged in the renewable energy teaching programs in Oldenburg and elsewhere.

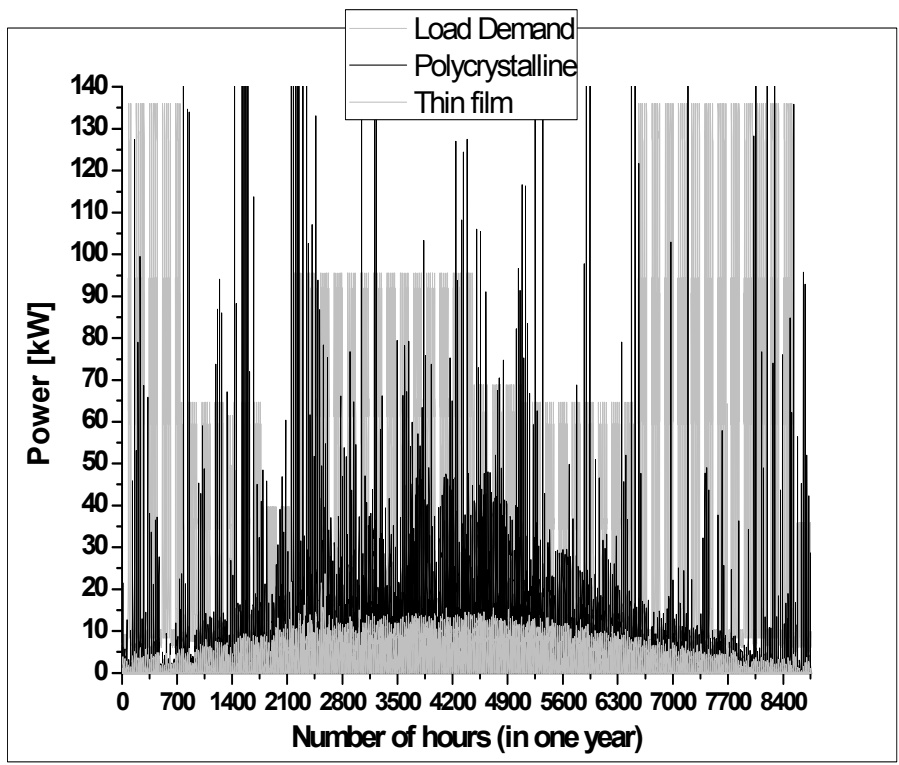

Fig. 4 Hourly electrical energy demand versus potential of solar PV technologies

\section{CONCLUSIONS}

Out of the resources assessed, only solar PV and solar thermal were found to generate substantial energy under the given site specific climatic conditions. The technical potential of wind energy resource was found to be poor for sustainable production of energy. Therefore, wind energy cannot be part of the energy portfolio to meet building energy demand. However, small scale wind turbines can be installed for didactical purposes as the proposed building is an educational facility. Although biogas and geothermal energies show some promising results, further detailed supply chain investigation should be carried out before including them in the building energy portfolio.

The problem of matching demand and supply is a serious challenge when large shares of renewable energy are included in the energy portfolio. Therefore, after this study, the authors recommend a detailed analysis of storage options, both thermal and electrical, in order to effectively manage the intermittency of renewable energy sources. Furthermore, the collective system design and integration of different energy options, as well as their collective economic analyses, were not undertaken during this study; these tasks remain to be carried out by the future batches of PPRE. 


\section{ACKNOWLEDGMENT}

PPRE 2012-14 \& 2011-13 batches, Jade Hochschule, PPRE staff and guest presenters for Case Study module. The authors also like to thank Jonas Stuehrenberg and Natalie Preissler for proof-reading the manuscript.

\section{REFERENCES}

[1] Brudler, Evelyn, et al. "24 years postgraduate program renewable energy."In. Developments in Renewable Energy Technology (ICDRET), 2012, 2nd International Conference on the, pp. 1-4. IEEE, 2012.

[2] (2013) The EWE website. [Online]. Available: http://www.ewe.de/ewe-macht-zukunft/ewe-zentrum-zukunft.php

[3] Space demand survey results as found out by previous batches after interviewing the staff of University of Oldenburg, adopted from HOL, 2013.

[4] Hot environments - Estimation of the heat stress on working man, based on the WBGT-index (wet bulb globe temperature), ISO 7243:1989

[5] PPRE 2012-2014, "The New Energy Lab”, Final Presentation - Case study module, Postgraduate Programme Renewable Energy, Jun. 2013. 